Int. J. Morphol.,

34(2):417-423, 2016.

\title{
Anthropometric Characteristics and Body Composition in Aikido Practitioners
}

\author{
Características Antropométricas y Composición Corporal en Practicantes de Aikido
}

Zdenko Reguli*; Martina Bernaciková* \& Michal Kumstát*

REGULI, Z.; BERNACIKOVÁ, M. \& KUMSTÁT, M. Anthropometric characteristics and body composition in aikido practitioners. Int. J. Morphol., 34(2):417-423, 2016.

SUMMARY: Although aikido is a non-competitive martial art, it is recognised by SportAccord as worldwide practiced combat sport. There is a lack of scientific research in aikido and the influence of aikido practice on the human body is not known. This is the first study that presents anthropometric characteristics and body composition data in aikido practitioners. 33 adult male aikido athletes (age $36.5 \pm 9.6$ years, height $178 \pm 8 \mathrm{~cm}$, weight $81.2 \pm 10.1 \mathrm{~kg}$ ) were measured. All subjects were divided from beginner to intermediate and advanced group, and were recruited from the Czech Aikido Federation which is officially recognised by the centre of aikido in Japan. As main methods, bio impedance and skinfold measurements were realized. In aikido, body composition does not play an important role compared to other martial arts. Average values are similar to reference of non-athlete population (BMI $25.6 \pm 2.7 \mathrm{~kg} / \mathrm{m}, \mathrm{BF} 17.18 \pm 5.18 \%$, FFM $65.71 \pm 7.69 \mathrm{~kg}$, BSA $1.98 \pm 0.15 \mathrm{~m}^{2}$ ). Even though, aikido has positive effects on body composition, it does not have a high impact. Thus, aikido players should also gain benefits from other aspects of martial arts.

KEY WORDS: Matiegka; Bioimpedance; Martial arts; Body mass.

\section{INTRODUCTION}

Most of global martial arts like judo, karate or taekwondo are also competitive sports. But there is an extraordinary one which is developed as non-competitive but rather cooperative martial art. Japanese martial aikido, developed in the middle of the $20^{\text {th }}$ century by its founder Morihei Ueshiba, as comprehensive martial art comprising mainly throws and falls, pins and joint locks and work with various weapons, including knife, staff and sword.

However, Aikido is a more "internal" (or "soft") style of martial art that features gentle, and flowing movements and differs from commonly known martial arts ("external" or "hard" styles) characterized by fast and explosive movements with a focus on physical strength and agility as it is in competitive combat sports such judo and wrestling.

Although Aikido is included into Sport Accord World Combat Games, there are only exhibitions, not competitions and no weight categories in Aikido. Additionally, Aikido is usually practised in mixed groups with no age selection and often among people at various performance levels. So we can expect a wide dispersion in anthropometric characteristics and body composition in any group of Aikido practitioners. Aikido group selected for the testing in this study was from the Czech Aikikai group, practising rather athletic, dynamic and fluid aikido.

There is only one way to measure performance in Aikido, by examination. In ranking system, there are 6th to $1^{\text {st }}$ kyu grades and $1^{\text {st }}$ to $10^{\text {th }}$ dan degrees. Second and first kyu grade holders are recognized as intermediate practitioners, all dan holders are recognised as advanced practitioners. Grading system in aikido is standardised according to Aikikai regulations.

Tanden, the centre, or belly (hara) is crucial term for practising aikido. According to the philosophy of aikido, tanden is the centre of vital power. One should develop strong and stable tanden (belly) to be good warrior. The extreme example of well-developed warrior is typical sumo wrestler (Kanehisa et al., 1998). On the other hand, there is in today's Japan ideal body shape of bishonen as it is seen in popular culture, or art, for example manga and anime. Bishonen is a young slender androgynous boy, but also intelligent, amusing and very strong in his martial abilities. Though Aikido brings a bit of Japanese culture abroad, the image of an ideal body

*Faculty of Sport Studies, Masaryk University, Brno, Czech Republic. 
shape is not part of it. There is neither literature nor shihan (master teacher) that mentions the ideal body shape or body composition.

Despite the fact, that there are no competitions in aikido, body mass evaluations are necessary in order to monitor body composition, nutritional status, training outcomes and general health. In this respect, fat mass (FM) and fat-free mass (FFM) are traditionally used to identify elementary nutritional requirements and energy expenditure in athletes. Body composition values might be used to develop specific dietary interventions or to help create, optimise and support training programs.

Currently the most commonly used laboratory methods for estimating body composition are densitometry, hydrostatic weighing, bioimpedance measurement (BIA) and DEXA. Bioelectrical impedance analysis method is noninvasive, relatively inexpensive, and safe and recently highly extended field method. Another tool to assess body composition is based on anthropometric measurements. This metric data, which may be determined in field practice usually includes skinfold measurement, girth and breadth measurement (Blaha et al., 1985). In this respect Matiegka (1921) proposed a model in which he divided body composition into four components (skeletal mass, fat mass, muscle mass and residue mass). Many other procedures to estimate body composition were set by various scientists since the Matiegka's method was developed, such as by Durnin \& Womersley (1974), Jackson et al. (1980), Lohman (1986) and Peterson et al. (2003). However, the original Matiegka's method or its modification according to Drinkwater et al. (1986) is still highly valid. The advantage of the skinfold measurements method or other anthropometric testing tools is useful in field based conditions, and in larger studies without placing excessive stress on the person tested (Riegerová et al., 2006). Even more, in recent publications Matiegka's method might still be recommended for determining muscle mass and skeletal mass (Eston \& Reilly, 2009).

With respect to the nature of aikido activity we recognised an absence of data dealing with body composition and anthropometric characteristics. There is no publication indexed in global databases such ISI or SCOPUS dealing with aikido somatotype or body composition. Limited interest of scientists in this area may be caused by the fact, that there is no requirement for higher performance from the media, or sponsors. Therefore, the aim of the study is to describe anthropometric characteristics and body composition with the use of girths, breadths and skinfolds measurements in a group of Czech adult aikido practitioners with different aikido experience.

\section{MATERIAL AND METHOD}

Subjects. The study sample was composed of 33 adult male aikido athletes (age $36.5 \pm 9.6$ years, height $178 \pm 8 \mathrm{~cm}$, weight $81.2 \pm 10.1 \mathrm{~kg}$, BMI $25.6 \pm 2.7$ ) and with $6^{\text {th }}$ to $1^{\text {st }} \mathrm{kyu}$ grades and $1^{\text {st }}$ to $5^{\text {th }}$ dan degrees. Athletes trained 2-4 times per week. Each training session lasted from about $1 \mathrm{~h}$ and 30 min to $2 \mathrm{~h}$ for all the subjects screened. The subjects were interviewed in order to collect data on age, training experience (in years) and sports level (dan, kyu), which was established on the basis of their examination ranking system. In the Czech Aikido Federation wearing wide pants hakama as a symbol of good performance is allowed from second kyu. Although we can expect slightly different understanding of advanced practice in dan holders, we divided all measured persons $(n=33)$ into three separate groups as follows:

$\begin{array}{ll}\text { - } & \text { Beginners - up to third kyu }(\mathrm{n}=7) \\ \text { - } & \text { Intermediate }- \text { second and first kyu }(\mathrm{n}=15) \\ \text { - } & \text { Advanced }- \text { dan holders }(\mathrm{n}=11)\end{array}$

All interviewed participants were informed about aim of the study and agreed to take part in an anthropological research.

Table I shows descriptive statistic of characteristic of male aikido practitioners (age, height, weight, BMI, BF, FFM and BSA) in aikido practitioners.

Anthropometric measurements. The measurements were taken as follows: all the measurements were taken in the morning after an overnight fast, at the same place (laboratory) and the subjects were barefoot on the measuring device wearing shorts only.

Body composition. Height measurement was made on a stadiometer Tanita (Tanita HR-001, Amsterdam, Netherlands) with accuracy of $0.01 \mathrm{~cm}$.

InBody scales (InBody 230, model: MW 160, Biospace, Korea) were used for measurements of weight (an accuracy of $0.01 \mathrm{~kg}$ ) and body composition by means of bioimpedance analysis (BIA). Direct segmental multifrequency BIA method separately measures the impedance of the trunk, arms, and legs of our body with the use of tetrapolar 8-point tactile electrode system. Overall it gives 10 impedance measurements by using 2 different frequencies $(20 \mathrm{kHz}$ and $100 \mathrm{kHz})$ at each of 5 segments (right arm, left arm, trunk, right leg and left leg). On the basis of the anthropometrical measurements, body mass index (BMI) was calculated. BIA is based on the premise that a low voltage, high frequency current presented into the human body is primarily conducted through the fat free mass (FFM). 
Table I. The characteristics of male aikido practitioners.

\begin{tabular}{lcc}
\hline \multirow{2}{*}{ Parameters } & \multicolumn{2}{c}{ Descriptive statistic $(\mathbf{n}=\mathbf{3 3})$} \\
\cline { 2 - 3 } & Mean \pm SD & Range \\
\hline Age (years) & $36.52 \pm 9.56$ & $20-56$ \\
Height $(\mathrm{cm})$ & $178.06 \pm 7.97$ & $162.5-201.0$ \\
Weight $(\mathrm{kg})$ & $81.17 \pm 9.95$ & $58.1-108.4$ \\
BMI $(\mathrm{kg} / \mathrm{m})$ & $25.61 \pm 2.70$ & $18.24-30.76$ \\
BF $(\%)$ & $17.18 \pm 5.18$ & $8.8-28.5$ \\
FFM $(\mathrm{kg})$ & $65.71 \pm 7.69$ & $51.7-86.1$ \\
BSA $\left(\mathrm{m}^{2}\right)$ & $1.98 \pm 0.15$ & $1.67-2.45$ \\
\hline
\end{tabular}

Legend: $\mathrm{BMI}=$ body mass index; $\mathrm{BF}=$ body fat; $\mathrm{FFM}=$ fat free mass; $\mathrm{BSA}=$ body surface area; to determine $\mathrm{BF}$ and FFM a bioimpedance analysis was used.

Among the known indirect methods of estimation of body fat (BF), muscle mass (MM), skeletal mass (SM) and residue mass (RM), standardized Matiegkas equation (see below) was chosen. Matiegka derived widely used and scientifically accepted anthropometric model to estimate total body muscle mass (Heymsfield, 2005). Skinfold measurement was performed two times (the mean value was taken) at the dominant side of the body using Best calliper (BEST II K501, Trystom, Czech Republic) with contact surface pressure of $20 \mathrm{~g} \cdot \mathrm{mm}^{-2}$ (an accuracy of $0.1 \mathrm{~mm}$ ). Triceps, biceps, forearm, chest, abdominal, mid-thigh and mid-calf skinfolds were assessed to determine body adiposity.

Limb girths were performed with a flexible tape measure (max upper arm girth, max forearm girth, mid-thigh girth, and max calf girth) and four skeletal breadths (biepicondylar humerus, bistyloideus, biepicondyal femur and bimalleolar) were measured using an anthropometer Trystom (Trystom, Czech Republic) with an accuracy of $0.01 \mathrm{~cm}$.

Body composition estimation procedure. Muscle mass (MM), skeletal mass (SM), fat mass (FM) and residue mass (RM) was estimated by the equation proposed by Matiegka.

Statistical analysis. Descriptive statistics was used. Mean values (X) and standard deviation (SD) of each parameter were calculated. The data obtained were statistically analysed in the Excel program and presented as mean, standard deviation (SD) and amplitude (minimum and maximum values). Standard statistical methods were used to calculate the mean and standard deviations. The normality of the variables was evaluated through the KolgomorovSmirnov test.

\section{RESULTS}

Table II shows descriptive statistic of main anthropometric data (girths, breadths and skinfolds) in the group of male aikido practitioners. To compare the results with a representative data we used Czech anthropometric reference data of men in the age of 35-45 years coming from the Blaha's cohort (Blaha et al.).

Table II. Girths, breadths, and skinfolds in the group of male aikido practitioners.

\begin{tabular}{llccc}
\hline \multirow{2}{*}{ Parameters } & & \multicolumn{2}{c}{ Descriptive statistic (n= 33) } & Ref. B $\mathbf{~}^{\mathbf{1}}$ (n) 145) \\
\cline { 2 - 4 } & & Mean \pm SD & Range & Mean \pm SD \\
\hline Girths (cm) & Relaxed upper arm & $32.17 \pm 3.06$ & $25.0-38.5$ & $30.7 \pm 2.28$ \\
& Max upper arm & $35.16 \pm 3.19$ & $26.5-41.5$ & $34.2 \pm 2.51$ \\
& Max forearm & $29.09 \pm 2.07$ & $24.5-33.5$ & $28.6 \pm 1.51$ \\
& Mid-thigh & $55.77 \pm 4.42$ & $44.5-64.0$ & $53.5 \pm 4.02$ \\
Breadths (cm) & $39.18 \pm 3.39$ & $32.0-48.0$ & $38.5 \pm 2.49$ \\
& Max calf & $7.21 \pm 0.37$ & $6.4-7.1$ & $7.2 \pm 0.45$ \\
& Biepicondylar humerus & $5.78 \pm 0.31$ & $5.0-6.3$ & $6.0 \pm 0.34$ \\
& Wrist & $9.90 \pm 0.40$ & $9.0-10.8$ & $10.1 \pm 0.55$ \\
& Biepicondylar femur & $7.62 \pm 0.44$ & $6.5-8.7$ & $7.5 \pm 0.41$ \\
& Ankle & $10.55 \pm 4.08$ & $5-23$ & $8.9 \pm 3.95$ \\
& Triceps & $6.85 \pm 2.88$ & $2-14$ & $5.0 \pm 3.19$ \\
& Biceps & $12.67 \pm 5.99$ & $3-27$ & $12.3 \pm 5.49$ \\
& Chest & $18.58 \pm 6.38$ & $6-34$ & $20.6 \pm 8.65$ \\
& Abdominal & $13.61 \pm 4.35$ & $6-24$ & $13.1 \pm 6.27$ \\
& Mid-thigh & $12.09 \pm 3.97$ & $5-22$ & $10.5 \pm 6.09$ \\
& Mid-calf & $13.30 \pm 3.96$ & $5-22$ & $15.0 \pm 6.14$ \\
& Subscapular & $13.21 \pm 6.37$ & $3-30$ & $12.8 \pm 6.15$ \\
& Supraspinale & $7.73-3.38$ & $3-15$ & $4.9 \pm 2.94$ \\
\hline
\end{tabular}

1Ref. $\mathrm{B}=$ Blaha's reference man; height $174.8 \pm 6.42 \mathrm{~cm}$, weight $80.3 \pm 9.66 \mathrm{~kg}$; adopted from Czech reference anthropometric data (Blaha et al., 1985) 
Table III shows descriptive statistic of Body composition using Matiegka's formulae for body fat, muscle mass, skeletal mass and residue mass. With respect to our results, Blaha's (Blaha et al.) reference data should be mentioned, because Mateigka's method had been used as an elementary anthropometric tool.

Table IV presents intergroup differences in body composition parameters. The sample was divided into beginners, intermediate and advanced group.

Table III. Body composition.

\begin{tabular}{|c|c|c|c|c|}
\hline \multirow{2}{*}{ Parameters } & & \multicolumn{2}{|c|}{ Descriptive statistic $(n=33)$} & \multirow{2}{*}{$\begin{array}{c}\text { Ref. } \mathbf{B}^{1}(n=145) \\
\text { Mean } \pm \text { SD }\end{array}$} \\
\hline & & Mean \pm SD & Range & \\
\hline \multirow{2}{*}{ Skeletal mass } & Absolute (kg) & $12.47 \pm 1.50$ & $9.3-16.5$ & $12.58 \pm 1.35$ \\
\hline & Relative (\%) & $15.45 \pm 1.45$ & $11.8-19.5$ & $15.67 \pm 1.07$ \\
\hline \multirow{2}{*}{ Muscle mass } & Absolute $(\mathrm{kg})$ & $36.98 \pm 5.65$ & $25.9-49.6$ & $35.64 \pm 5.19$ \\
\hline & Relative (\%) & $45.51 \pm 3.50$ & $36.8-54.3$ & $44.38 \pm 1.45$ \\
\hline \multirow{2}{*}{ Fat mass } & Absolute $(\mathrm{kg})$ & $15.46 \pm 5.44$ & $5.5-28.5$ & $13.06 \pm 5.46$ \\
\hline & Relative (\%) & $18.77 \pm 5.35$ & $8.5-30.5$ & $16.26 \pm 4.18$ \\
\hline \multirow{2}{*}{ Residue mass } & Absolute $(\mathrm{kg})$ & $16.25 \pm 3.62$ & $9.6-23.3$ & $17.01 \pm 1.40$ \\
\hline & Relative (\%) & $20.77 \pm 4.63$ & $9.8-26.4$ & $23.69 \pm 2.06$ \\
\hline
\end{tabular}

1Ref. B= Blaha's reference man; height $174.8 \pm 6.42 \mathrm{~cm}$, weight $80.3 \pm 9.66 \mathrm{~kg}$; adopted from Czech reference anthropometric data (Blaha et al., 1985).

Table IV. Body composition in different-level aikido groups.

\begin{tabular}{llcc}
\hline \multirow{2}{*}{ Parameters (\%) } & \multicolumn{3}{c}{ Descriptive statistic $^{\mathbf{1}}$} \\
\cline { 2 - 4 } & Sample group & Mean (SD) & Range \\
\hline \multirow{2}{*}{ Skeletal mass } & Advanced & $15.1 \pm 0.8$ & $13.7-16.3$ \\
& Intermediate & $15.2 \pm 1.6$ & $11.8-18.7$ \\
& Beginners & $16.4 \pm 1.7$ & $15.0-19.5$ \\
Muscle mass & Advanced & $45.7 \pm 4.8$ & $36.8-54.3$ \\
& Intermediate & $45.0 \pm 2.7$ & $40.0-49.4$ \\
\multirow{2}{*}{ Fat mass } & Beginners & $46.2 \pm 2.9$ & $42.2-50.2$ \\
& Advanced & $19.6 \pm 3.1$ & $13.3-26.8$ \\
\multirow{2}{*}{ Residue mass } & Intermediate & $21.1 \pm 5.3$ & $11.2-30.5$ \\
& Beginners & $12.4 \pm 3.1$ & $8.5-16.9$ \\
& Advanced & $19.5 \pm 3.4$ & $14.2-25.1$ \\
& Intermediate & $18.7 \pm 5.1$ & $9.8-25.8$ \\
\hline
\end{tabular}

$1=$ Acoording to Matiegka's (1921) formulae; $2=$ Sample sizes: beginners $(n=7)$, intermediate $(n=15)$, advanced $(n=11)$.

\section{DISCUSSION}

Generally, laboratory and field methods are used to estimate body composition. Most of the laboratory methods such as hydrostatic weighing, dual-energy X-ray absorptiometry (DEXA), air-displacement plethysmography or total body potassium count are impractical to use in large populations or sport-specific settings. These laboratory body composition methods are expensive and inconvenient. Body composition field methods, such as bioelectric impedance analysis (BIA) and skinfold measurement become the first choice of sports staff professionals who are interested in the fat and fat-free composition of athletes. These techniques are likely to be used, because of convenience, low cost and ease of practice. However, field methods, such as anthropometric measurements (skinfolds and circumferences) and BIA are prone to estimation errors. In athletes it is therefore important to control for testing conditions such as hydration status.

Like skinfold equations, BIA equations require validation, since they indirectly assess body composition and are therefore population specific. In a recent review by Moon it is suggested to focus on the development of general athlete-specific equations, however it is concluded that using a BIA method shows promise for estimating body composition in athletes (Moon, 2013). Currently BIA technique lacks comprehensive normal range data on variety of sports, including martial arts. We chose standardized Matiegka's method, because this method estimates body composition according to the four basic components. If we consider differences that we found between skinfold measurement and BIA, fat mass significantly differs with higher values obtained via skinfold measurement, than using BIA, e.g. $18.7 \%$ vs. $17.1 \%$, respectively $(\mathrm{p}=0.02)$. However this difference is of small size effect and with little practical impact on overall aikido performance. Moreover as we demonstrate in Tables II and III, all measured anthropometric characteristics are generally consistent with accepted Czech reference anthropometric data (Blaha $e t$ al.).

Table V shows a comparison of selected anthropometric characteristics in martial art studies (e.g. 


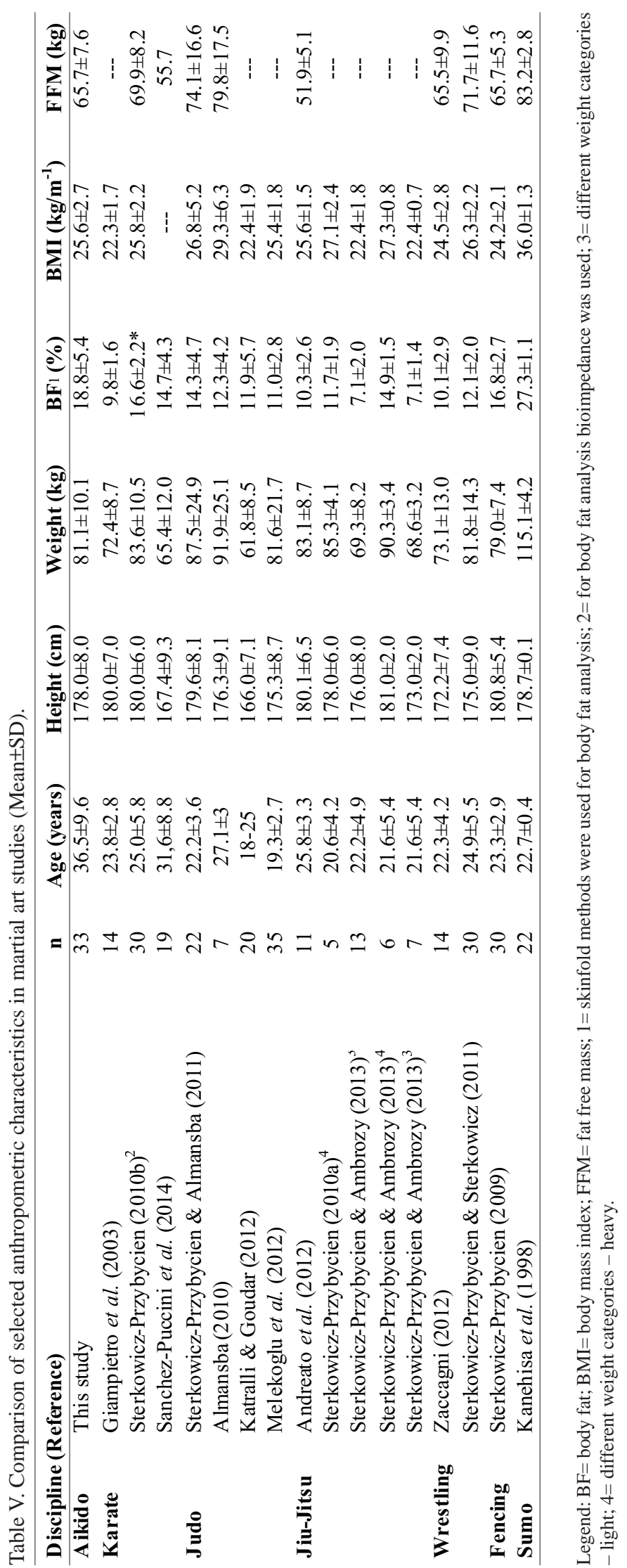

karate, judo, jiu-jitsu, wrestling, fencing and sumo) found in recent literature.

In aikido study group, not consistent with others, we show wide age range. This is expected in traditional non-competition martial art discipline such as aikido. Compared to other martial art studies, the Czech aikidokas were older. It is given by the fact, that aikido as a martial art is a lifelong learning activity. The possibility for high performance is not restricted by age.

In our group we found similar height as in studies with karate players (Giampietro, 2003; Sterkowicz-Przybycien, judo players (SterkowiczPrzybycien \& Almansba, 2011; Almansba et al., 2010), jiu jitsu practitioners (Andreato et al., 2012; Sterkowicz-Przybycien, 2010a) and sumo wrestlers (Kanehisa et al.). Wrestlers were found to be smaller (Zaccagni, 2012; Sterkowicz-Przybycien \& Sterkowicz, 2011), which might be explained by lower centre of mass. On the contrary higher posture was measured in fencers (Kordi et al., 2009).

Body weight found in our study was with relation to body height similar to judo athletes (Katralli \& Goudar, 2012) and wrestlers (Sterkowicz-Przybycien \& Sterkowicz, 2011). However this is highly dependent on weight category and may not be used as a comparable parameter. Higher body weight was measured in judo athletes (Sterkowicz-Przybycien \& Almansba, 2011; Almansba et al.). The highest body weight was understandably presented in Sumo wrestlers (Kanehisa et al.). As there are no competitions in aikido, there is also no need to make weight, as is obvious in other competitive combat sports (Kordi et al.).

It was found that in judo, which is the most similar to aikido in technique, a mean percentage body fat $(14.3 \%)$ was slightly lower than that for our sample of subjects $(18.8 \%)$ (Sterkowicz-Przybycien \& Almansba, 2011). Lower values were generally published in judo athletes (Almansba et al.; Katralli \& Goudar; Melekoglu et al., 2012). Karate contestants, who had similar body weight to our aikido participants had approximately the same level of body fat $16.6 \%$, despite the fact that the sample consisted of elite-level karate contestants (Sterkowicz-Przybycien, 2010b). In a group of fencers $16.8 \%$ body fat was measured (Sterkowicz-Przybycien, 2009). Lower percentage of body fat was found out in jiu-jitsukas too. Again, not surprisingly higher values $(27.3 \%)$ were measured in sumo wrestlers (Kanehisa et al.). 
Most of studies provide data about BMI. Higher values of BMI were naturally found out in sumo wrestlers $\left(36.0 \mathrm{~kg} \cdot \mathrm{m}^{-1}\right)($ Kanehisa et al.), with not much diversity among other martial arts discipline (Table V). Despite the fact that some martial arts athletes are overweight, and exceeding the normal range of BMI, it must be however noted that this is mainly due to the competitive weight class categories and higher level of muscle mass fraction.

Compared to other martial art studies, the Czech aikidokas had lower FFM. It may be demonstrated by comparison with karatekas (Sterkowicz-Przybycien, 2010b), judokas (Sterkowicz-Przybycien \& Almansba, 2011; Almansba et al.) and sumo wrestlers (Kanehisa et al.). Similar FFM was found out in wrestlers (Zaccagni; SterkowiczPrzybycien et al.) and fencers (Sterkowicz-Przybycien, 2009). Only two studies showed lower FFM, it was in jiu-jitsu (Andreato et al.) and karate (Sanchez-Puccini et al., 2014).

Under comparison to girths, we came to the conclusion that aikido participations had calf girth and flexed upper arm girth quite similar to judokas (Sterkowicz-Przybycien \& Almansba, 2011) and jiu-jitsukas (Andreato et al.). Similar flexed upper arm girth was measured in wrestlers (Zaccagni) and forearm girth was found to be comparable again to the group of jiu-jitsu athletes (Andreato $e t a l$.).
If we compare selected breadths, clear consistency may be found with biepicondylar humerus breadth and biepicondylar femur in judokas (Sterkowicz-Przybycien \& Almansba) and jiu-jitsukas (Andreato et al.). When analysing breadths among various martial arts disciplines in detail, it may be concluded that karate contestants have generally lower values Sanchez-Puccini et al.

Compared to Indian Judo players (Katralli \& Goudar), the Czech aikidokas had similar skin folds in triceps (10.6 vs. $10.5 \mathrm{~mm})$, in thigh (13.6 vs. $12.4 \mathrm{~mm})$ and in medial calf $(12.0$ vs. 12.0). Resembling subscapular skin folds (13.8 vs. 13.3 $\mathrm{mm}$ ) were found in jiu-jitsu elite athletes (Andreato et al.).

\section{CONCLUSIONS}

This is the first study that presents anthropometric characteristics and body composition data in aikido practitioners. We show that there are similarities with some martial arts disciplines, such as jiu jitsu. However, aikido practitioner's body composition is not much different to the reference average of non-athlete counterparts, even in the sub-group of advanced athletes. This demonstrates the fact, that body composition is not as important as might be seen in other martial arts disciplines.

REGULI, Z.; BERNACIKOVÁ, M. \& KUMSTÁT, M. Características antropométricas y composición corporal en practicantes de aikido. Int. J. Morphol., 34(2):417-423, 2016.

RESUMEN: A pesar de que el aikido es un arte marcial no competitivo, es reconocido por SportAccord como un deporte de combate practicado en todo el mundo. Existe escasa investigación científica sobre el aikido y la influencia de su práctica en el cuerpo humano. Este es el primer estudio que presenta las características antropométricas y datos de composición corporal en practicantes de Aikido. Se midieron 33 hombres adultos, atletas de aikido (edad 36,5 $\pm 9,6$ años, altura $178 \pm 8 \mathrm{~cm}$, peso $81,2 \pm 10,1 \mathrm{~kg}$ ). Los sujetos fueron divididos en los grupos: principiante, intermedio y avanzado, reclutados desde la Federación Checa de Aikido, que es reconocida oficialmente por el centro de aikido en Japón. Como métodos principales, se realizaron mediciones de bioimpedancia y pliegues cutáneos. En el aikido, la composición corporal no juega un rol importante en comparación con otras artes marciales. Los valores promedio fueron

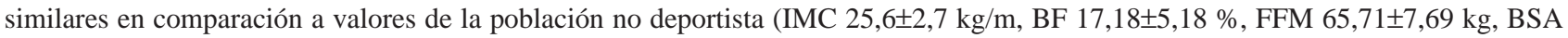
$1,98 \pm 0,15 \mathrm{~m}^{2}$ ). A pesar de que el aikido tiene efectos positivos en la composición corporal, no tiene un alto impacto. Por lo tanto, los atletas de aikido deberían también obtener beneficios de otros elementos de las artes marciales.

PALABRAS CLAVE: Matiegka; Bioimpedancia; Artes marciales; Masa corporal.

\section{REFERENCES}

Almansba, R.; Sterkowicz, S.; Sterkowicz-Przybycien, K. \& Mahdad, D. Anthropometrical and physiological profiles of the Algerian Olympic judoists. Arch. Budo, 6(4):185-93, 2010.

Andreato, L. V.; Franchini, E.; Moraes, S. M. F.; Esteves, J. V. C.; Pastório, J. J.; Andreato, T. V.; Gomes, T. L. M. \& Vieira, J. L. P. Morphological profile of Brazilian Jiu-Jitsu elite athletes. Rev. Bras. Med. Esporte, 18(1):46-50, 2012.
Blaha, P.; Sedivy, V.; Cechovsky, K. \& Kosová, A. Anthropometric studies of the Czechoslovak population from 6 to 55 years. Prague, Czechoslov Spartakiade, 1985.

Drinkwater, D. T.; Martin, A. D.; Ross, W. D. \& Clarys, J. P. Validation by cadaver dissection of Matiegka's equations for the anthropometric estimation of anatomical body composition in adult humans. In: Day, J. A. P. (Ed.). 
Perpectives Kinanthropometry: The 1984 Olympic Scientific Congress Proceedings, Vol. 1. Champaign IL, Human Kinetics, 1986. pp.221-7.

Durnin, J. V. \& Womersley, J. Body fat assessed from total body density and its estimation from skinfold thickness: measurements on 481 men and women aged from 16 to 72 years. Br. J. Nutr., 32(1):77-97, 1974.

Eston, R. G. \& Reilly, T. Kinanthropometry and Exercise Physiology Laboratory Manual. Vol. 1: Tests, Procedures, and Data. London, Routledge, 2009.

Giampietro, M.; Pujia, A. \& Bertini, I. Anthropometric features and body composition of young athletes practicing karate at a high and medium competitive level. Acta Diabetol., 40(Suppl. 1):S145-8, 2003.

Heymsfield, S.; Lohman, T.; Wang, Z. M. \& Going, S. Human Body Composition. Champaign IL, Human Kinetics, 2005.

Jackson, A. S.; Pollock, M. L. \& Ward, A. Generalized equations for predicting body density of women. Med. Sci. Sports Exerc., 12(3):175-81, 1980.

Kanehisa, H.; Kondo, M.; Ikegawa, S. \& Fukunaga, T. Body composition and isokinetic strength of professional Sumo wrestlers. Eur. J. Appl. Physiol. Occup. Physiol., 77(4):352-9, 1998.

Katralli, J. \& Goudar, S. S. Anthropometric Profile and special judo fitness levels of indian judo players. Asian J. Sports Med., 3(2):113-8, 2012.

Kordi, R.; Maffulli, N.; Wroble, R. R. \& Wallace, W. A. Combat Sports Medicine. Dordrecht, Springer, 2009. pp.358.

Lohman, T. G. Applicability of body composition techniques and constants for children and youths. Exerc. Sport Sci. Rev., 14:325-57, 1986

Matiegka, J. The testing of physical efficiency. Am. J. Phys. Anthropol., 4(3):223-30, 1921.

Melekoglu, T.; Öcal, D.; Baydil, B. \& Sönmez, M. Muscle strength in relation to body composition in the turkish male national judo team. Ovidius Univ. Ann. Ser. Phys. Educ. Sport Science, 12(2):175, 2012.

Moon, J. R. Body composition in athletes and sports nutrition: an examination of the bioimpedance analysis technique. Eur. J. Clin. Nutr., 67 (Suppl. 1):S54-9, 2013.

Peterson, M. J.; Czerwinski, S. A. \& Siervogel, R. M. Development and validation of skinfold-thickness prediction equations with a 4-compartment model. Am. J. Clin. Nutr., 77(5):1186-91, 2003.
Riegerová, J.; Pridalová, M. \& Ulbrichová, M. Aplikace Fyzické Antropologie V Telesné Vychove A Sportu (Prírucka Funkcní Antropologie). Olomouc, Hanex, 2006.

Sánchez-Puccini, M. B.; Argothy-Bucheli, R. E.; Meneses-Echávez, J. F.; López-Albán, A.C. \& Ramírez-Vélez, R. Anthropometric and physical fitness characterization of male elite karate athletes. Int. J. Morphol., 32(3):1026-31, 2014.

Sterkowicz-Przybycien, K. \& Almansba, R. Sexual dimorphism of anthropometrical measurements in judoists vs untrained subject. Sci. Sports, 26(6):316-23, 2011.

Sterkowicz-Przybycien, K. \& Ambrozy, T. Sexual dimorphism in anthropometric and fitness measurements of top ju-jitsu contestants. J. Combat Sports Martial Arts, 4(2):145-51, 2013.

Sterkowicz-Przybycien, K. L.; Sterkowicz, S. \& Zarów, R. T. Somatotype, body composition and proportionality in polish top greco-roman wrestlers. J. Hum. Kinet., 28:141-54, 2011.

Sterkowicz-Przybycien, K. Body composition and somatotype of the elite of Polish fencers. Coll. Antropol., 33(3):765-72, 2009.

Sterkowicz-Przybycien, K. Technical diversification, body composition and somatotype of both heavy and light Polish ju-jitsukas of high level. Sci. Sports, 25(4):194-200, 2010a.

Sterkowicz-Przybycien, K. Body composition and somatotype of the top of polish male karate contestants. Biol. Sport, 27(3):195201, 2010b.

Zaccagni, L. Anthropometric characteristics and body composition of Italian national wrestlers. Eur. J. Sport Sci., 12(2):145-51, 2012.

Correspondence to:

Zdenko Reguli

Department of Gymnastics and Combatives

Faculty of Sport Studies

Masaryk University

Kamenice 753/5, 62500

Brno

CZECH REPUBLIC

Email: reguli@fsps.muni.cz

Received: 23-02-2016

Accepted: 05-04-2016 